\title{
Article \\ Computational Study of the Therapeutic Potential of Novel Heterocyclic Derivatives against SARS-CoV-2
}

\author{
Benjamin Ayodipupo Babalola ${ }^{1, * \mathbb{D}}$, Tosin Emmanuel Adetobi ${ }^{2}$, Oluwamayowa Samuel Akinsuyi ${ }^{3}$, \\ Otunba Ahmed Adebisi ${ }^{4}$ and Elizabeth Oreoluwa Folajimi 5
}

1 Department of Biological Sciences, College of Basic and Applied Sciences, Mountain Top University, Obafemi-Owode, Lagos 110106, Ogun, Nigeria

2 Department of Anatomy, Faculty of Basic Medical Sciences, College of Health Sciences, University of Ilorin, Ilorin 240003, Kwara, Nigeria; 16-46ka024@students.unilorin.edu.ng

3 Department of Microbiology and Cell Science, University of Florida, Gainsville, FL 32611, USA; o.akinsuyi@ufl.edu

4 Daniel and Fola Biotechnology Foundation, Makoko, Lagos 101245, Ogun, Nigeria; hadbat2.oa@gmail.com

5 Department of Microbiology, Faculty of Life Sciences, University of Ilorin, Ilorin 240003, Kwara, Nigeria; 15-55ej096@students.unilorin.edu.ng

* Correspondence: bababalola@mtu.edu.ng or benjaminayodipupo@gmail.com

check for updates

Citation: Babalola, B.A.; Adetobi, T.E.; Akinsuyi, O.S.; Adebisi, O.A.; Folajimi, E.O. Computational Study of the Therapeutic Potential of Novel Heterocyclic Derivatives against SARS-CoV-2. COVID 2021, 1, 757-774 https://doi.org/10.3390/covid1040061

Academic Editor: Cheng-Wen Lin

Received: 18 October 2021

Accepted: 25 November 2021

Published: 16 December 2021

Publisher's Note: MDPI stays neutral with regard to jurisdictional claims in published maps and institutional affiliations.

Copyright: (c) 2021 by the authors. Licensee MDPI, Basel, Switzerland. This article is an open access article distributed under the terms and conditions of the Creative Commons Attribution (CC BY) license (https:// creativecommons.org/licenses/by/ $4.0 /)$.

\begin{abstract}
Severe Acute Respiratory Syndrome Coronavirus- 2 (SARS-CoV-2), including the recently reported severe variant B.1.617.2, has been reported to attack the respiratory tract with symptoms that may ultimately lead to death. While studies have been conducted to evaluate therapeutic interventions against the virus, this study evaluated the inhibitory potential of virtually screened novel derivatives and structurally similar compounds towards SARS-CoV-2 via a computational approach. A molecular docking simulation of the inhibitory potentials of the compounds against the SARS-CoV-2 drug targets-main protease (Mpro), spike protein (Spro), and RNA-dependent RNA polymerase (RdRp)—-were evaluated and achieved utilizing AutoDock Vina in PyRx workspace. The absorption, distribution, metabolism, excretion, and toxicity (ADMET) properties of these compounds were assessed using SwissADME and ADMETLab servers. All the compounds displayed high binding affinities for the SARS-CoV-2 drug targets. However, the $\mathrm{C} 13$ exhibited the highest binding affinity for the drug targets, Spro and RdRp, while C15 exhibited the highest binding affinity for Mpro. The compounds interacted with the LEU A:271, LEU A:287, ASP A:289, and LEU A:272 of Mpro and the HIS A:540, PRO A:415, PHE A:486, and LEU A:370 of the Spro receptor binding motif and some active site amino acids of RdRp. The compounds also possess a favourable ADMET profile and showed no tendency towards hERG inhibition, hepatotoxicity, carcinogenicity, mutagenicity, or drug-liver injury. These novel compounds could offer therapeutic benefits against SARS-CoV-2, and wet laboratory experiments are necessary to further validate the results of this computational study.
\end{abstract}

Keywords: drug discovery; drug target; molecular docking; SARS-CoV-2

\section{Introduction}

In December 2019, several cases of pneumonia of unknown etiology were reported in Wuhan, China. The outbreak, which was reported to have commenced in late December 2019 in China, was soon worldwide, with increased cases and deaths [1]. The causative agent of the outbreak earned the name SARS-CoV-2 after being identified as a beta coronavirus whose genomic sequence was closely aligned to severe acute respiratory syndrome coronavirus (SARS-CoV), earlier identified in 2003 [1-3]. SARS-CoV-2 has been identified as the seventh coronavirus known to infect humans [4]; SARS-CoV, Middle East respiratory syndrome coronavirus (MERS-CoV), and SARS-CoV-2 have been reported to be severe, while human coronavirus (HCov)-HKU1, HCov-NL63, HCoV-OC43, and HCoV-229E are mild [5]. As of 5:52 pm CEST, 11 October 2021, the WHO had identified 237,383,711 confirmed cases of COVID-19, including 4,842,716 deaths globally [6]. 
SARS-CoV-2, including the recently reported severe variant B.1.617.2 [7,8], attacks the respiratory tract with symptoms ranging from breathing difficulties, sore throat, high fever, diarrhea, and cough to multiple organ failure and ultimately death [9]. This can occur when the spike protein (Spro), which possesses an S1 domain and an S2 subunit, binds to angiotensin-converting enzyme-2 (ACE-2) receptors on the surface of the host alveoli to allow for entry [10]. Thus, studies have identified the Spro as a drug target to prevent interaction with ACE-2, thereby inhibiting the entry of the virus [11,12]. Furthermore, with the aid of RNA-dependent RNA polymerase (RdRp), the viral RNA translation results in the synthesis of proteins responsible for synthesizing new virions from single-stranded RNA, which makes RdRp a primary drug target to prevent viral growth and replication $[13,14]$. Overall, viral studies have shown that viral proteases are typical targets for anti-viral drug development $[15,16]$. Hence, the main protease (Mpro) of SARS-CoV-2, which plays a role in viral replication, could be a potential therapeutic target $[17,18]$.

In this study, computational tools are utilized instead of the traditional methods of developing and discovering new therapeutic agents. The latter is more involved, requires rigorous scientific procedures, and may be time-consuming. However, the bioinformatics approach is viable for designing and developing new drugs of biomedical interest as it predicts the binding affinities and ADMET (absorption, distribution, metabolism, excretion, and toxicity) properties of test compounds to protein receptors and domains $[19,20]$.

Heterocyclic compounds play an essential role in drug discovery and development; hence, great work has gone into developing simple and environmentally friendly methods for their high yielding production [21]. For example, compounds derived from azetidine have shown to have a diverse range of pharmacological activities, such as anticancer [22], antibacterial [23,24], antimicrobial [25], antischizophrenic [26], antimalarial [27,28], antiobesity [29,30], anti-viral [31], antioxidant [31], and dopamine antagonist [32] activity, amongst others. They are also reported to be tRNA-synthetase inhibitors, signal transducers and activators of transcription-3 (STAT-3) inhibitors, and vascular endothelial growth factor receptor-2 (VEGFR-2) inhibitors [31,33-35]. Other heterocyclics, such as cyclic amidine and guanidine also possess biological potency [36,37]. Heterocyclic skeletons of promising pharmacological importance usually contain nitrogen, sulphur, and oxygen as they represent a major proportion of the bioactive heterocyclic compounds and marketed drugs [21]. Azetidine, amidine, and gunanine rings are nitrogen-containing heterocyclic organic compounds with different synthetic strategies and pharmaceutical importance $[31,32,37,38]$. As a result, pharmaceutical companies incorporate these compounds into the design, formulation, development, and synthesis of drugs. Specifically, the antiproliferative properties of azetidine derivatives have prompted their use and production in anti-viral research $[31,39,40]$. Their anti-viral activities are aided by their ability to inhibit proteins essential to the viral life cycle [41,42]. Some of these heterocyclic drugs with anti-viral activities have been approved by the FDA. In 2018, the FDA approved baricitinib, a heterocyclic derivative of azeitidine, to treat patients with rheumatoid arthritis [31]. Recently, baricitinib was found to engender early stabilization of the respiratory functions and reduce rehospitalization and the mortality rate resulting from COVID-19 at a daily high dose [43]. Barticinib combined with other drugs has been found to control the virus. Treatment of the virus with baricitinib plus hydroxychloroquine was associated with recovery in 11 of 15 patients [44]. Treatment with baricitinib plus dexamethasone resulted in the reduced mortality of COVID-19 drugs [45]. Moreover, Baricitinib plus remdesivir was reported to be superior to remdesivir alone as it reduces recovery time and accelerates improvement in clinical status among patients with COVID-19, notably among those receiving high-flow oxygen or noninvasive ventilation [46].

In this study, owing to the urgency for further therapeutic interventions against the coronavirus, a computational approach was employed to evaluate the therapeutic potential of specific novel heterocyclic derivatives against SARS-CoV-2. 


\section{Materials and Methods}

\subsection{Ligand Derivatives}

A total of 500 compounds derived in relation to azetidine were obtained from the NCBI database. They were viewed on the PubChem database (https:/ / pubchem.ncbi.nlm. nih.gov, accessed on 1 July 2021) and filtered by adjusting the molecular weight in $\mathrm{g} / \mathrm{mol}$, hydrogen bond acceptor count, $\log \mathrm{P}$, rotatable bond count, heavy atom count, hydrogen bond donor count, polar area, and complexity, using the five rules of drugability (Lipinski, Veber, Ghose, Varma, and Opera's rule), which resulted in 89 lead-like analogues.

\subsection{Ligand Preparation}

The canonical SMILES of the 89 lead-like compounds obtained from the virtual screening were converted into the MOL SDF format using OpenBabel [47] and Chemdes [48]. This study used the co-crystallized ligand (PDB: N3) extracted from the main protease as a standard ligand; the other standard ligand used in this study was remdesivir (PubChem IDs = 121304016) (Figure 1). The MOL SDF format of the compounds and standard ligands were uploaded to PyRx software (v0.9.8, SouceForge, Sab Diego, CA, USA) and converted to PDBQT format using the OpenBabel plugin (v2.3.1, Solvusoft Corporation, Las Vegas, NV, USA). The output files were minimized at a force field, UFF, to obtain minimum energy for the ligand docking. After the molecular docking analysis to determine the binding affinities of the ligands, 17 compounds were found to have the highest binding affinity (Figure 2).
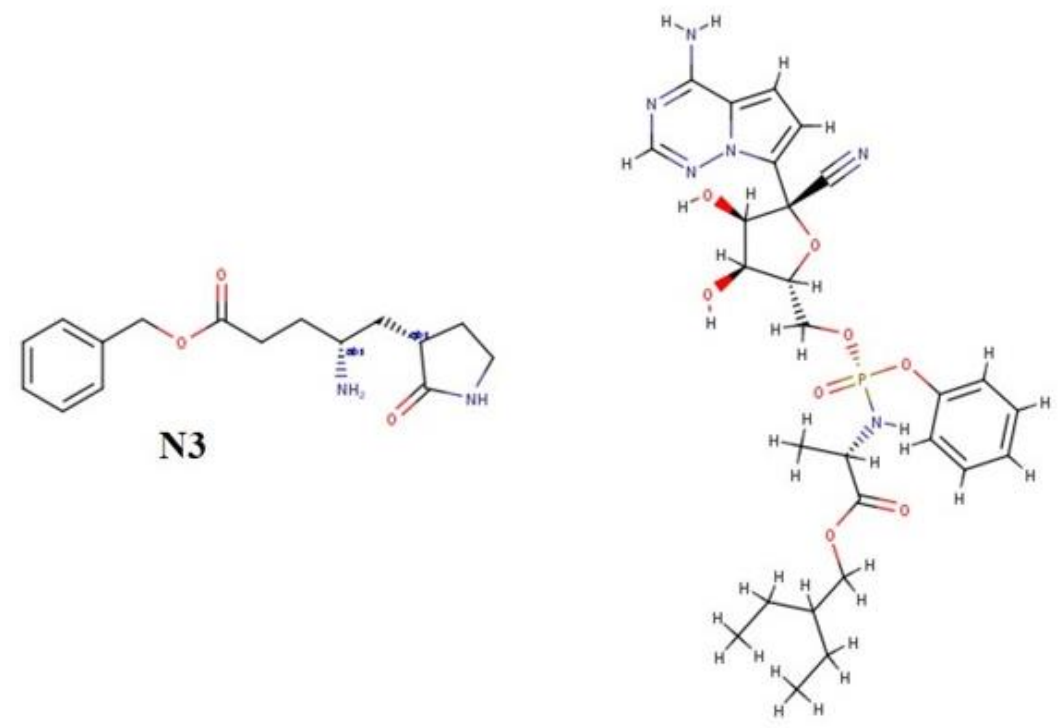

Remdesevir

Figure 1. Structure of standard ligands. 
<smiles>COc1ccc(CNc2ccc(C(=O)c3c[nH]c4ncccc34)cn2)cn1</smiles>

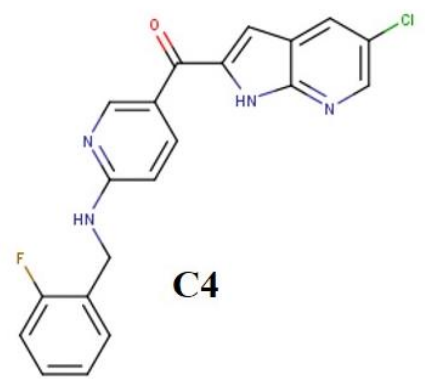<smiles>Cc1ccccc1CNc1ccc2ncc(-c3ccc(O)cc3)nc2n1</smiles><smiles>Cc1ccc(S(=O)(=O)CC(=O)O)cc1</smiles><smiles>Cc1ccc(CNc2ccc3ncc(-c4ccc(O)cc4)nc3n2)cc1</smiles><smiles>CNCc1cccc(-c2ccccc2C)c1F</smiles><smiles>CNc1nc2c3ccc(F)cc3c3c(=O)[nH]ccc3c2s1</smiles><smiles>COc1ccc(CNc2nc3c4ccc(F)cc4c4c(=O)[nH]ccc4c3o2)cc1</smiles><smiles>COc1ccccc1CNc1nc2c3ccc(F)cc3c3c(=O)[nH]ccc3c2o1</smiles><smiles>C=c1nc(NCc2ccc(Cl)cc2)nc2c1=C(C)CCN2c1ccccc1</smiles><smiles>CC(C)(C)c1ccc(CNc2ncc3c(n2)CCc2cnc4[nH]ncc4c2-3)cc1</smiles><smiles>Clc1ccccc1CNc1ncc2c(n1)CCc1cnc3[nH]ncc3c1-2</smiles><smiles>Clc1ccc(CNc2ncc3c(n2)CCc2cnc4[nH]ncc4c2-3)cc1Cl</smiles>

Figure 2. Cont. 


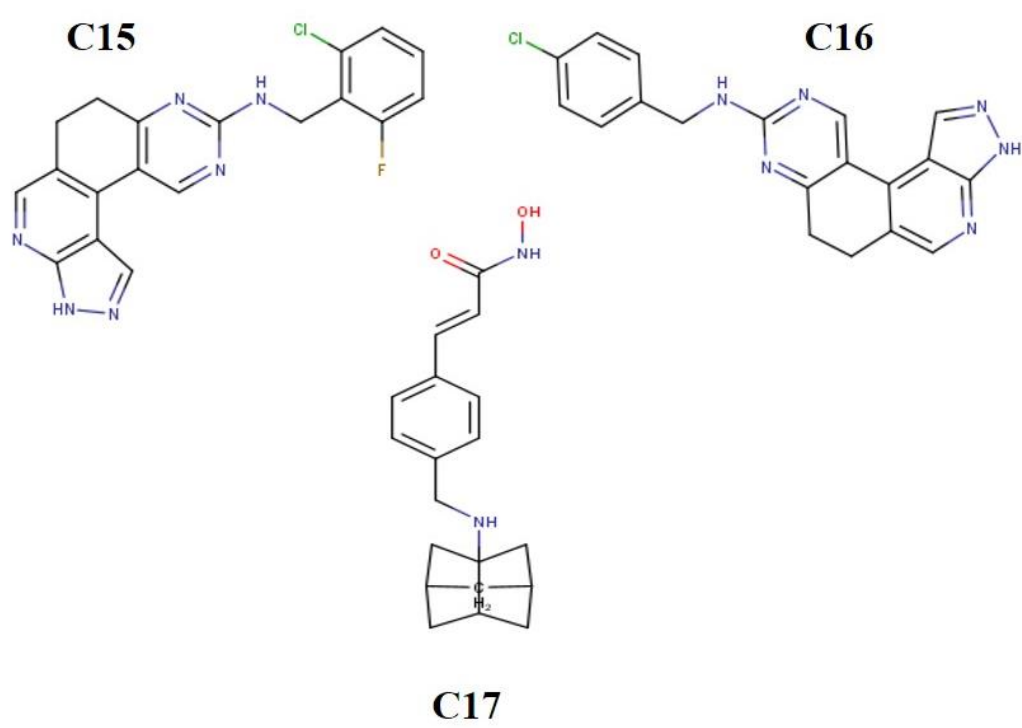

Figure 2. Structure of heterocyclic derivatives from virtual screening.

\subsection{Protein Preparation}

The protein targets for this study are the SARS-CoV-2 Main protease (Mpro:6LU7), RNA polymerase (RdRp: 6M71), and spike protein (Spro: 6LZG). The structures of these proteases were obtained from the RCSB Protein Data Bank (PDB) repository (https: / /www. rcsb.org/, accessed on 29 July 2021). MPro was in complex with N3, a co-crystallized ligand used as a standard. The other targeted proteins were also obtained from the same repository with the IDs 6LZG for the spike protein and 6M71 for the RNA polymerase.

The PDB format of the proteins was uploaded to the PyMol visualization tool workspace (v2.5.2, Schrodinger, Inc., New York, NY, USA), where other non-standard residues, including ions, water, and bounded ligands extracted from the active binding pocket by set measures were removed. The prepared protein was then uploaded to the PyRx software for molecular docking analysis.

\subsection{Molecular Docking}

After preparing the target protein and ligands, molecular docking analysis was conducted using AutoDock Vina (Scripps Research, La Jolla, CA, USA) in the PyRx workspace tool, based on scoring functions [49]. The energy of the ligands was minimized and then converted to the PDBQT. The ligands and the receptors were selected for docking analysis at the resolution of the grid box, which was taken along the $x, y$, and $z$ axes, respectively, at a maximised dimension of $79.2749 \times 84.5415 \times 106.0303 \AA, 62.3892 \times 69.5557 \times 70.0574 \AA$, $51.3737 \times 66.9738 \times 58.6069 \AA$ for the RNA polymerase, the spike protein, and the main protease, respectively, to accurately define the binding site of the targeted receptors. The spike model dimension was selected to optimize the search space to achieve the highest accuracy for the experimental pocket and those predicted from the protein structure. These parameters were set to cover the entire 3-dimensional active site of the proteins and ensure the ligand exactly bound to the active site of the targets. The standards were first docked against each receptor, and the resulting interaction was compared with that of the lead-like analogues in the same binding site using the same grid box dimensions. Furthermore, the complexes derived from the ligands and the receptors' docking pose were visualized to analyze the interactions and bonds between the receptor and the ligands using the BIOVIA Discovery Studio21 (Dassault Systèmes, San Diego, CA, USA). 


\subsection{Validation of Docking Protocol}

The docking pose obtained from the PyRx docking tool was validated by redocking some of the standard and test ligands into the catalytic domain or the binding site of the proteins used for the study using the PyRx tool [49].

\subsection{ADMET Predictions}

The compounds' absorption, distribution, metabolism, excretion, and toxicity (ADMET) properties were determined utilizing model predictions on the SwissADME [50] and the ADMETLab server [51], respectively.

\section{Results}

\subsection{Binding Affinities and Stability of Test Compounds with SARS-CoV-2 Drug Targets}

The compounds exhibited various levels of binding affinities $(\Delta \mathrm{G} \mathrm{kcal} / \mathrm{mol})$, ranging from -8.8 to -8.0 for Mpro (6LU7), -10.6 to -9.7 for Spro (6LZG), and -9.5 to -8.7 for RdRp (6M71). Among the heterocyclics, compound C13 exhibits the highest binding affinity for the drug targets Spro $(-10.6 \mathrm{kcal} / \mathrm{mol})$ and $\operatorname{RdRp}(-9.5 \mathrm{kcal} / \mathrm{mol})$, respectively. At a binding affinity of $-8.8 \mathrm{kcal} / \mathrm{mol}$, compound $\mathrm{C} 15$ exhibits the highest binding affinity for Mpro. Moreover, compounds C12 and C14 exhibit high binding affinities towards the Mpro target at -8.7 and $-8.6 \mathrm{kcal} / \mathrm{mol}$. Moreover, towards Spro, compounds C11 and $\mathrm{C} 4$ exhibit high binding affinities at -10.3 and $-10.2 \mathrm{kcal} / \mathrm{mol}$. For the RdRp target, compounds $\mathrm{C} 9$ and $\mathrm{C} 15$ exhibit high binding affinities at -9.0 and $-8.9 \mathrm{kcal} / \mathrm{mol}$. Overall, as reported in Table 1, the selected compounds gave binding affinities higher than those of the standard inhibitors.

Table 1. Binding affinities $(\Delta \mathrm{G}$ in $\mathrm{kcal} / \mathrm{mol}$ ) of test compounds for SARS-CoV-2 drug targets.

\begin{tabular}{|c|c|c|c|}
\hline \multirow{2}{*}{ Compounds } & \multicolumn{3}{|c|}{$\Delta \mathrm{G}$ Energy $(\mathrm{Kcal} / \mathrm{mol})$} \\
\hline & Mpro (6LU7) & Spro (6LZG) & $\operatorname{RdRp}(6 \mathrm{M} 71)$ \\
\hline \multicolumn{4}{|c|}{ Standard ligands } \\
\hline Remdesivir & -7.1 & -6.8 & -7.6 \\
\hline N3 & -7.3 & -6.3 & -5.6 \\
\hline \multicolumn{4}{|l|}{ Derivatives } \\
\hline $\mathrm{C} 1$ & -7.3 & -9.7 & -8.1 \\
\hline $\mathrm{C} 2$ & -7.3 & -10.1 & -8.9 \\
\hline $\mathrm{C} 3$ & -8.1 & -9.3 & -8.4 \\
\hline $\mathrm{C} 4$ & -7.9 & -10.2 & -8.5 \\
\hline C5 & -7.5 & -9.8 & -8.7 \\
\hline C6 & -8.2 & -9.2 & -8.3 \\
\hline $\mathrm{C} 7$ & -7.6 & -9.8 & -7.5 \\
\hline $\mathrm{C} 8$ & -7.9 & -9.5 & -8.9 \\
\hline C9 & -7.6 & -9.4 & -9.0 \\
\hline $\mathrm{C} 10$ & -8.0 & -8.8 & -8.6 \\
\hline C11 & -7.8 & -10.3 & -8.5 \\
\hline $\mathrm{C} 12$ & -8.7 & -9.4 & -8.9 \\
\hline $\mathrm{C} 13$ & -8.3 & -10.6 & -9.5 \\
\hline $\mathrm{C} 14$ & -8.6 & -9.1 & -8.7 \\
\hline $\mathrm{C} 15$ & -8.8 & -9.6 & -8.9 \\
\hline $\mathrm{C} 16$ & -8.4 & -9.8 & -8.8 \\
\hline $\mathrm{C} 17$ & -7.1 & -9.9 & -7.6 \\
\hline
\end{tabular}

\subsection{Molecular Docking Analysis of Selected Test Compounds}

Figures 3-5 show the three-dimensional (3D) and two-dimensional (2D) structures of the SARS-CoV-2 target proteins in complex with the standard inhibitors and the three compounds with the highest affinities (compounds C15, C12, and C14 for Mpro; compounds C13, C11, and C4 for Spro; and compounds C13, C9, and C15 for RdRp). 

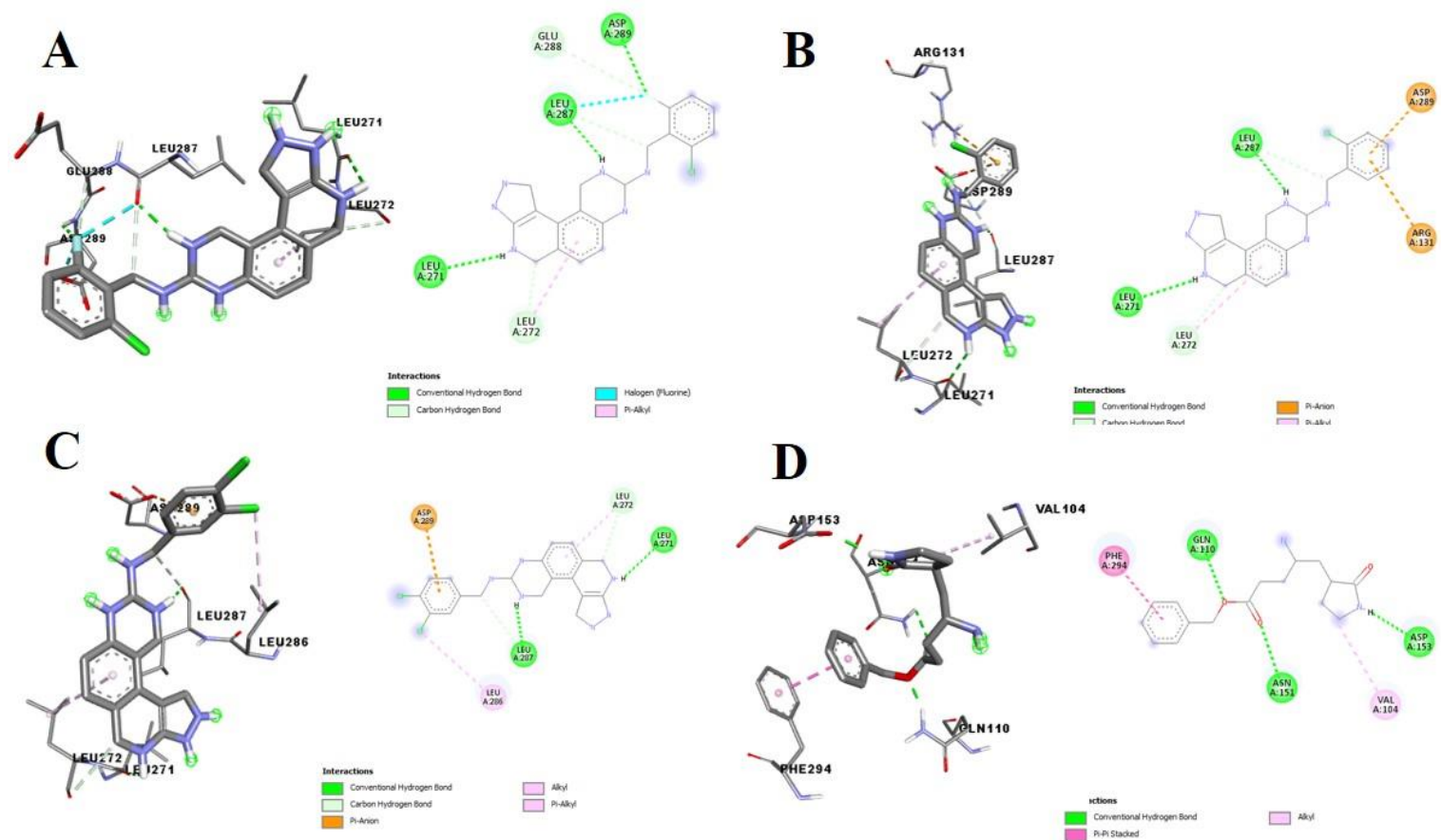

\section{D}

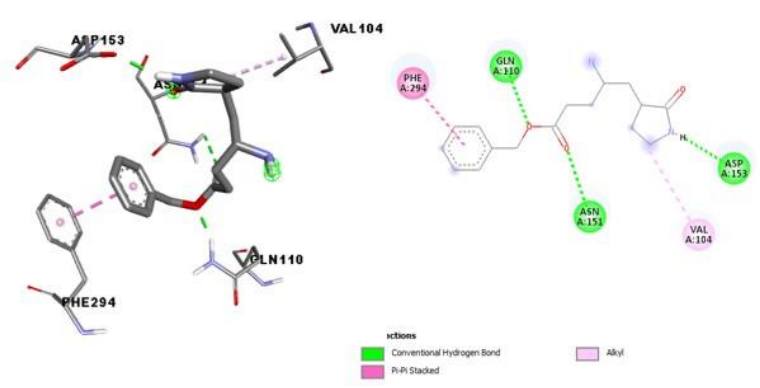

Figure 3. 3D (left) and 2D (right) views of the molecular interactions of amino-acid residues of Mpro (6LU7) with (A) C15, (B) C12, (C) C14, and (D) N3.
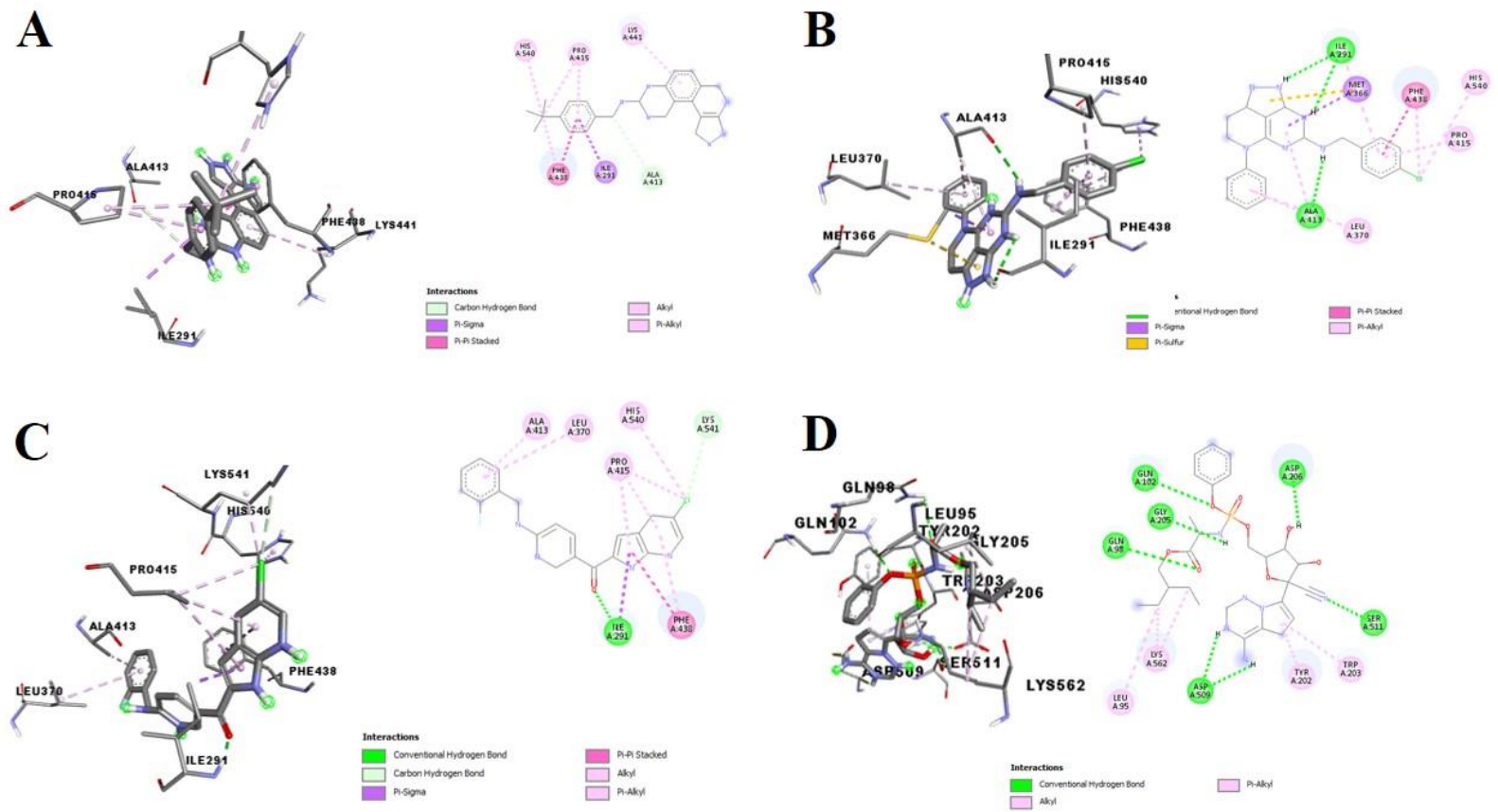

Figure 4. 3D (left) and 2D (right) views of the molecular interactions of amino-acid residues of Spro (6LZG) with (A) C13, (B) C11, (C) C4, and (D) remdesivir. 

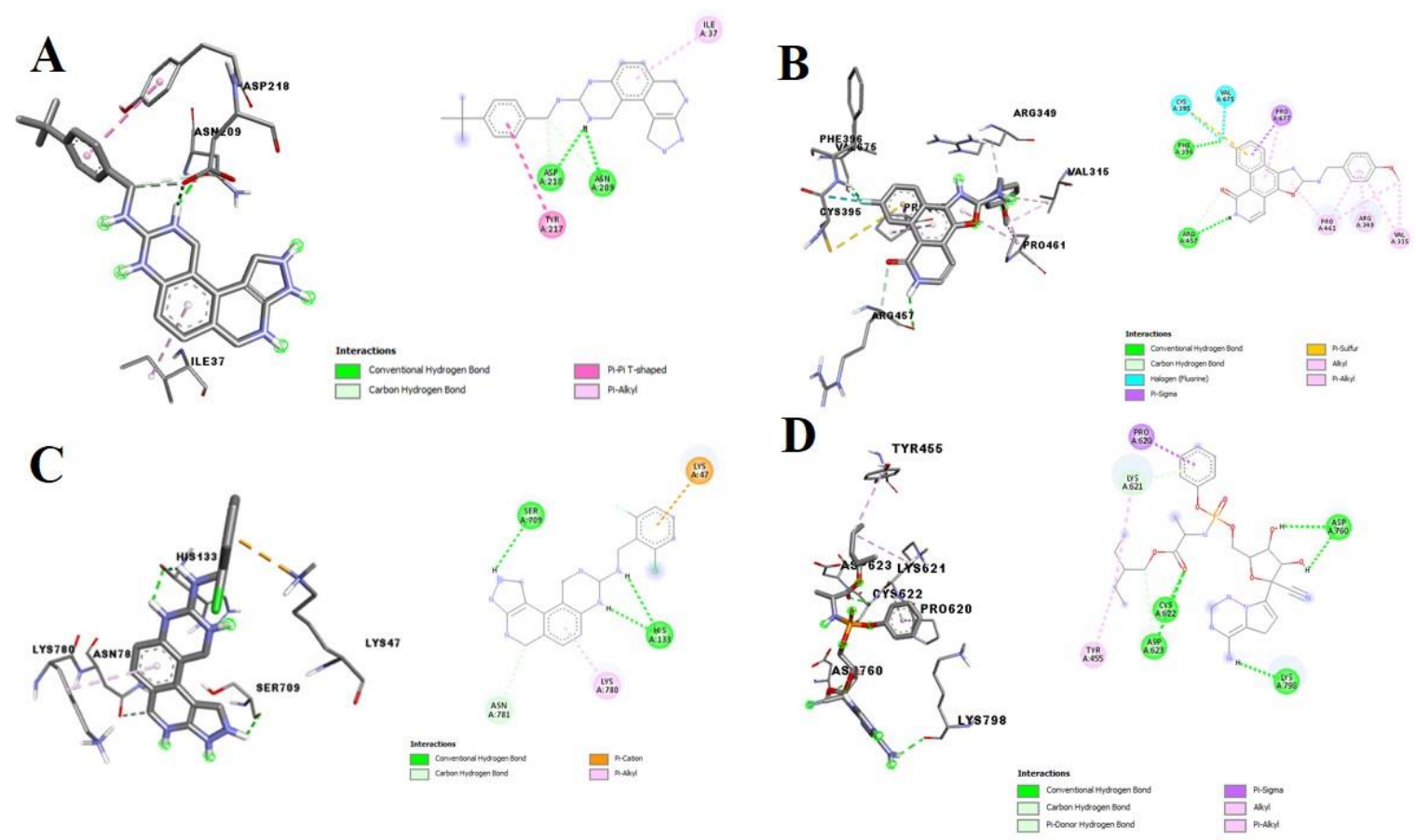

Figure 5. 3D (left) and 2D (right) views of the molecular interactions of amino-acid residues of RdRp (6M71) with (A) C13, (B) C9, (C) C15, and (D) remdesivir.

$\mathrm{C} 15, \mathrm{C} 12$, and C14 interacted via conventional hydrogen bonding, carbon-hydrogen bonds, and пा-alkyl bonds with LEU A:271, LEU A:287, ASP A:289, and LEU A:272 and other amino acid residues at the binding pocket of the inhibitor (N3) binding site of SARS-CoV-2 Mpro (Figure 3). The SARS-CoV-2 Spro formed a complex with C13, C11, $\mathrm{C} 4$, and remdesivir through various interactions with some amino acid residues of its receptor-binding domain (RBD) (Figure 4). HIS A:540, PRO A:415, PHE A:486, and LEU A:370, amongst other residues of Spro, formed п-alkyl interactions with C13, C11, and C4 (Figure $4 \mathrm{~A}-\mathrm{C}$ ), while remdesivir similarly interacted with the amino acid residue, via conventional hydrogen bonds and $\pi$-alkyl bonds (Figure 4D). Furthermore, C2, C8, C11, and remdesivir interacted with some amino acid residues at the binding pocket of SARSCoV-2 RdRp, including VAL A:675, PRO A:677, SER A:709, ASP A:216, ASN A:209, TYR A:217, ILE A:37, PHE A:396, ARG A:457, CYS A:395, PRO A:461, ARG A:349, VAL A:315, HIS A: 133, LYS A:47, SER A:709, HIS A:133, LYS A:780, TYR A:455, PRO A:620, and VAL A:315, amongst others, via hydrogen interaction, $\Pi-$-ninteractions, halogen interactions, alkyl interactions, and п-alkyl interactions (Figure 5).

\subsection{Validation of Docking Protocol}

Figures 6 and 7 illustrate the validation of the docking protocol and the aforementioned efficiency. Some of the test compounds and standard ligands were re-docked into the catalytic domain or binding site of the target protein docked pose obtained from the PyRx docking tool. The compounds C15, C13, C16, N3, and remdesivir bound exactly to the active sites of Mpro, Spro, RdRp, RdRp, and Spro, respectively, with binding affinities of $-8.8,-10.6,-8.8,-7.3$, and $-6.3 \mathrm{kcal} / \mathrm{mol}$. Upon superimposition of the re-docked complexes on the aforementioned respective compounds, the binding affinities of -8.3 , $-10.2,9.0,-7.1$, and $6.4 \mathrm{kcal} / \mathrm{mol}$ were observed, respectively, in the same order. The result shows a significant overlap of all the compounds (Figures 6 and 7) when re-docked at a minimized energy into their respective docked complex. 


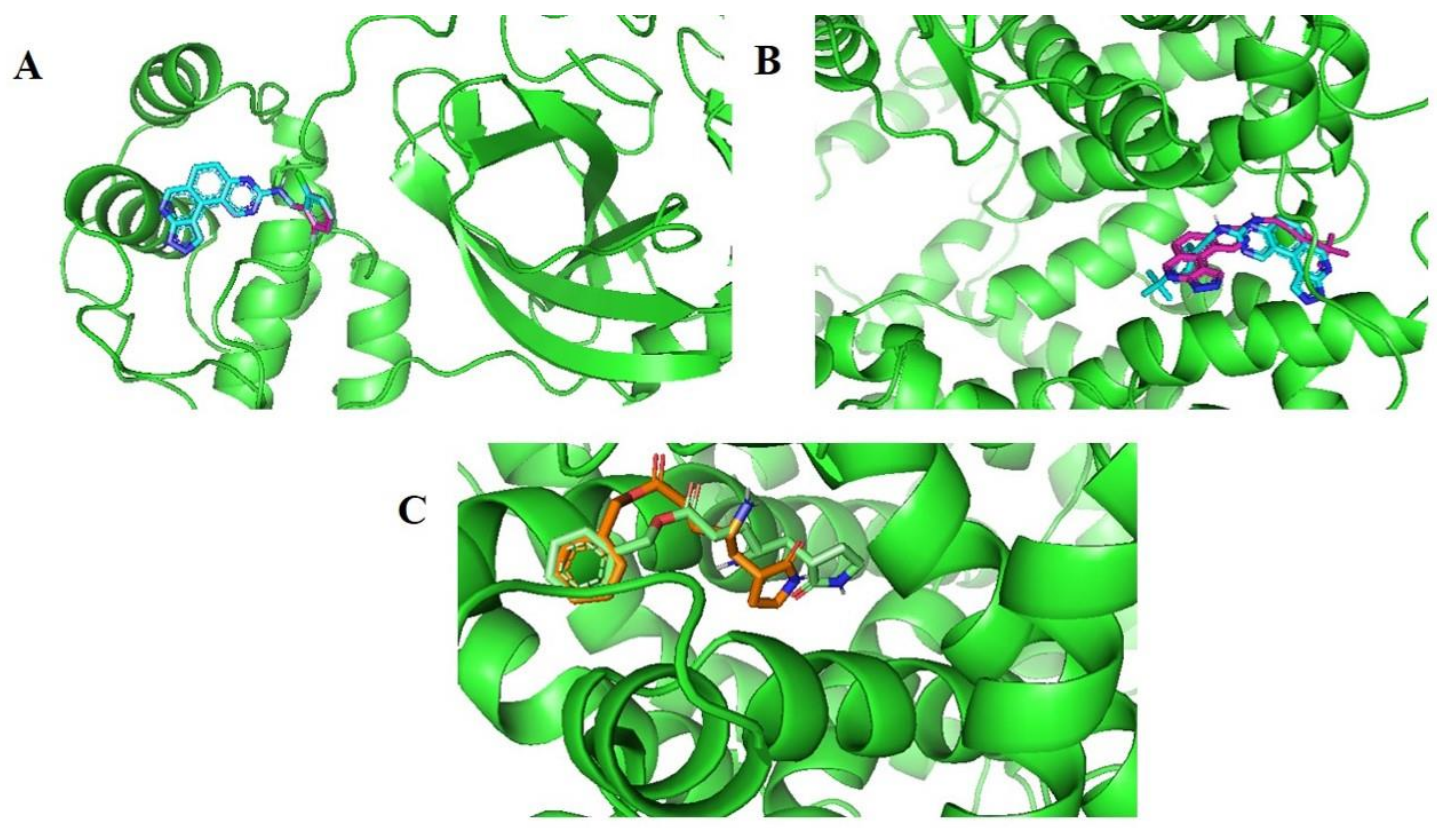

Figure 6. Molecular validation of docking protocol: comparability of the re-docked binding mode of (A) C15 in Mpro binding pocket, (B) C13 in Spro binding pocket, and (C) C16 in RdRp binding pocket.

A

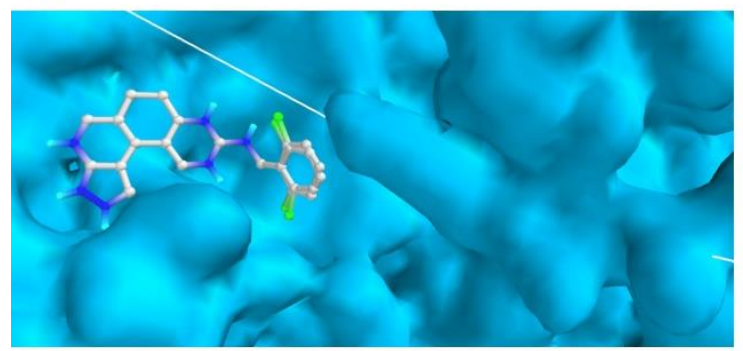

C

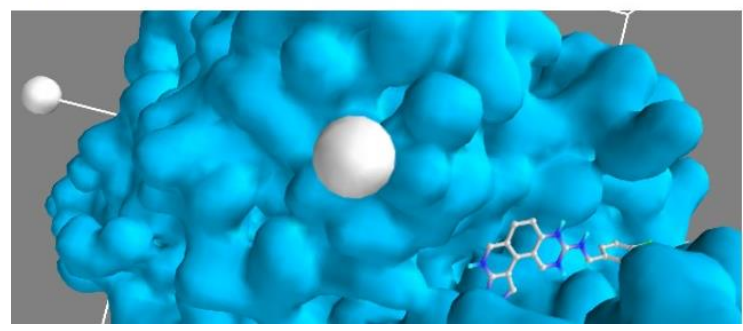

B

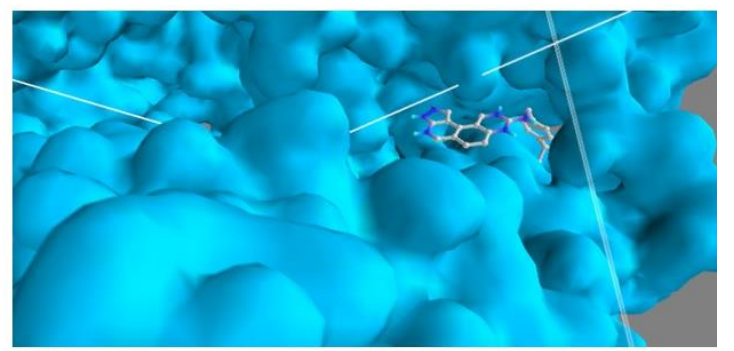

D

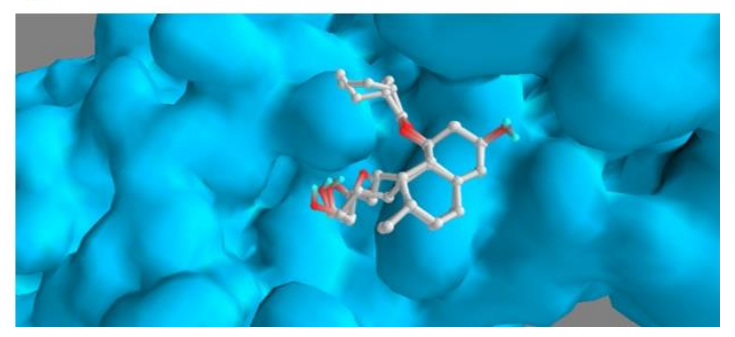

Figure 7. Visualised 3D validation of docking protocol: comparability of the re-docked binding mode of (A) C15 in Mpro binding pocket, (B) C13 in Spro binding pocket, (C) N3 in RdRp binding pocket, and (D) remdesivir in Spro binding pocket.

\subsection{ADMET Profile}

Table 2 shows the SwissADME predicted lipophilicity, water-solubility, drug-likeness, and bioavailability scores of the compounds. The selected test compounds have Log $p$ values as high as 4.10 (C9) and 3.98 (C4), with the least value being 3.27 (C5). However, compared to the standard ligands, the Log P values, which ranged between 3.27 and 4.10, were higher than the standard ligands, which ranged between 1.48 and 2.36. As with remdesivir, all the selected test compounds, $\mathrm{C} 4, \mathrm{C} 9, \mathrm{C} 11, \mathrm{C} 12, \mathrm{C} 13, \mathrm{C} 14$, and $\mathrm{C} 15$, are moderately soluble. N3 is soluble. For the drug-likeness prediction, none of the selected derived compounds violated Lipinski's, Ghose's, Veber's, Egan's, or Muegge's rules. For the bioavailability prediction, all the selected derivatives had a score of $0.55 \%$. 
Table 2. Predicted lipophilicity (Log P), water solubility (Log Sw), drug-likeness, and bioactivity of selected compounds and standard ligands.

\begin{tabular}{|c|c|c|c|c|c|c|c|c|c|}
\hline Parameters & $\mathrm{C} 4$ & C9 & C11 & $\mathrm{C} 12$ & $\mathrm{C} 13$ & C14 & C15 & N3 & Remdesivir \\
\hline Molecular weight $(\mathrm{g} / \mathrm{mol})$ & 380.8 & 389.38 & 376.84 & 362.82 & 384.48 & 397.26 & 380.81 & 290.36 & 602.58 \\
\hline Consensus Log P & 3.98 & 4.1 & 3.63 & 3.27 & 3.93 & 3.78 & 3.55 & 1.48 & 1.56 \\
\hline Log Sw (Silicos-IT) & 5.03 & 5 & 3.72 & 4.22 & 4.92 & 4.85 & 4.63 & 2.35 & -0.05 \\
\hline \#Heavy atoms & 27 & 29 & 27 & 26 & 29 & 27 & 27 & 21 & 42 \\
\hline \#Aromatic heavy atoms & 21 & 23 & 21 & 21 & 21 & 21 & 21 & 6 & 15 \\
\hline Fraction Csp3 & 0.05 & 0.09 & 0.15 & 0.16 & 0.3 & 0.16 & 0.16 & 0.5 & 0.48 \\
\hline \#H-bond acceptors & 4 & 5 & 3 & 4 & 4 & 4 & 5 & 4 & 12 \\
\hline \#H-bond donors & 2 & 2 & 2 & 2 & 2 & 2 & 2 & 2 & 4 \\
\hline MR & 102.52 & 109.88 & 110.72 & 101.54 & 115.8 & 106.55 & 101.49 & 83.47 & 150.43 \\
\hline TPSA (Å2) & 70.67 & 80.15 & 69.73 & 79.38 & 79.38 & 79.38 & 79.38 & 81.42 & 213.36 \\
\hline Lipinski violations & 0 & 0 & 0 & 0 & 0 & 0 & 0 & 0 & 2 \\
\hline Ghose violations & 0 & 0 & 0 & 0 & 0 & 0 & 0 & 0 & 3 \\
\hline Veber violations & 0 & 0 & 0 & 0 & 0 & 0 & 0 & 0 & 2 \\
\hline Egan violations & 0 & 0 & 0 & 0 & 0 & 0 & 0 & 0 & 1 \\
\hline Muegge violations & 0 & 0 & 0 & 0 & 0 & 0 & 0 & 0 & 3 \\
\hline Synthetic availability & 2.75 & 3.07 & 3.13 & 3.04 & 3.45 & 3.07 & 3.11 & 2.9 & 6.33 \\
\hline
\end{tabular}


Table 3 shows the results of the pharmacokinetics prediction of the test compounds. As highlighted in the table, the skin permeation values ( $\log \mathrm{Kp}$ in $\mathrm{cm} / \mathrm{s}$ ) of the test compounds ranged from -6.04 (more permeant) to -5.27 (most permeant). Compounds C11 and C14 are the most skin permeant of all the compounds; however, the range of values of each test compound suggested that they are all permeable compared to the values from the standard ligand. All the test compounds possess high GI absorption potential, and three of the compounds (C4, C11, and C14) displayed the ability to penetrate the blood-brain barrier. All the test compounds were substrates of Pgp except for compound C4. Moreover, all the test compounds were predicted to be inhibitors of CYP1A2, CYP2C19, CYP2C9, CYP2D6, and CYP3A4, except that compound C12 is not an inhibitor of CYP2C9.

Table 3. Pharmacokinetics prediction output of test compounds.

\begin{tabular}{llllllllll}
\hline Parameters & C4 & C9 & C11 & C12 & C13 & C14 & C15 & N3 & Remdesivir \\
\hline GI Absorption & High & High & High & High & High & High & High & High & Low \\
Blood-brain permeant & Yes & No & Yes & No & No & Yes & No & No & No \\
Pgp substrate & No & Yes & Yes & Yes & Yes & Yes & Yes & Yes & Yes \\
CYP1A2 inhibitor & Yes & Yes & Yes & Yes & Yes & Yes & Yes & No & No \\
CYP2C19 inhibitor & Yes & Yes & Yes & Yes & Yes & Yes & Yes & No & No \\
CYP2C9 inhibitor & Yes & Yes & Yes & No & Yes & Yes & Yes & No & No \\
CYP2D6 inhibitor & Yes & Yes & Yes & Yes & Yes & Yes & Yes & No & No \\
CYP3A4 inhibitor & Yes & Yes & Yes & Yes & Yes & Yes & Yes & No & Yes \\
Skin permeant Log Kp $(\mathrm{cm} / \mathrm{s})$ & -5.46 & -5.62 & -5.27 & -6.04 & -5.42 & -5.27 & -6.07 & -7.50 & -8.62 \\
\hline
\end{tabular}

As shown in Table 4, none of the test compounds tends to the human ether-a-go-gorelated gene (hERG), potassium channel inhibition (except for C4), mutagenesis, hepatotoxicity, and drug-induced liver injury.

Table 4. Toxicity profile prediction of test compounds.

\begin{tabular}{|c|c|c|c|c|c|c|c|c|c|}
\hline Parameters & $\mathrm{C} 4$ & C9 & C11 & $\mathrm{C} 12$ & $\mathrm{C} 13$ & C14 & C15 & N3 & Remdesivir \\
\hline hERG-Blockers & - & - & - & - & - & - & - & - & - \\
\hline H-HT (Human Hepatotoxicity) & - & - & - & - & - & - & - & - & - \\
\hline AMES (Ames Mutagenicity) & - & - & - & - & - & - & - & - & - \\
\hline LD50 (LD50 of acute toxicity) & $\begin{array}{l}2.503-\mathrm{log} \\
\mathrm{mol} / \mathrm{kg} \\
(1195.937 \\
\mathrm{mg} / \mathrm{kg})\end{array}$ & $\begin{array}{l}2.616-\log \\
\mathrm{mol} / \mathrm{kg} \\
(942.712 \\
\mathrm{mg} / \mathrm{kg})\end{array}$ & $\begin{array}{l}\text { 2.569-log } \\
\mathrm{mol} / \mathrm{kg} \\
(1016.646 \\
\mathrm{mg} / \mathrm{kg})\end{array}$ & $\begin{array}{l}2.579-\mathrm{log} \\
\mathrm{mol} / \mathrm{kg} \\
(956.524 \\
\mathrm{mg} / \mathrm{kg})\end{array}$ & $\begin{array}{l}\text { 2.704-log } \\
\mathrm{mol} / \mathrm{kg} \\
(760.119 \\
\mathrm{mg} / \mathrm{kg})\end{array}$ & $\begin{array}{l}2.651-\mathrm{log} \\
\mathrm{mol} / \mathrm{kg} \\
(887.329 \\
\mathrm{mg} / \mathrm{kg})\end{array}$ & $\begin{array}{l}2.598-\log \\
\mathrm{mol} / \mathrm{kg} \\
(960.977 \\
\mathrm{mg} / \mathrm{kg})\end{array}$ & $\begin{array}{l}\text { 2.452-log } \\
\mathrm{mol} / \mathrm{kg} \\
(1025.513 \\
\mathrm{mg} / \mathrm{kg})\end{array}$ & $\begin{array}{l}2.989-\mathrm{log} \\
\mathrm{mol} / \mathrm{kg} \\
(618.042 \\
\mathrm{mg} / \mathrm{kg})\end{array}$ \\
\hline DILI (Drug Induced Liver Injury) & - & - & - & - & - & - & - & - & - \\
\hline $\begin{array}{l}\text { FDAMDD (Maximum } \\
\text { Recommended Daily Dose) }\end{array}$ & - & - & - & - & - & - & - & - & - \\
\hline
\end{tabular}

$(-)=$ Inactive $(+)=$ Active

\section{Discussion}

As a result of the increased cases and mortality rates resulting from the global health challenge, the coronavirus, there have been responses to the emergency call to develop mitigation strategies for the infection. Some of the strategies being used to control the viral spread of the disease are the recommended use of face masks, hand gloves, and sanitizers. While quite a number of vaccines are being developed to stimulate the production of antibodies against the virus, there are still concurrent investigations exploring the therapeutic potential of some anti-viral agents, including remdesivir [52,53]. As the search for new anti-SARS-CoV-2 drugs continues, the use of heterocyclic organic compounds in anti-viral drug development is essential as they have been reported to be efficacious against other major viral infections $[31,54,55]$. Heterocyclic derivatives, such as guanine, cyclic amidine, and azetidine exhibit anti-viral activity as they inhibit the regulation of the enzymes and proteins associated with the life cycle of viruses $[31,56]$. Some of these heterocyclic derivatives have been approved by the US Food and Drug Administration (FDA) for treatment of some diseases. In 2017, delafloxacin was approved to treat patients with acute bacterial skin infections [31]. The FDA also approved the calcium channel blocker, azelnidipine, alone, or 
combined with other antihypertensive drugs, to treat hypertension [31]. In 2018, the FDA approved baricitinib to treat patients with rheumatoid arthritis, and it has been found to stabilize the respiratory functions of COVID-19 patients at a daily high dose [31,43].

The high binding affinities exhibited by the test compounds towards the SARS-CoV-2 target proteins in this study indicate the inhibitory potential of these compounds against these biomolecules and their possible roles as therapeutic agents against SARS-CoV-2. In addition, this study observed that $\mathrm{C} 13$ possesses a higher binding affinity for the Spro and RdRp target proteins than for the other compounds, while $\mathrm{C} 15$ has a higher binding affinity for Mpro. This could be linked to the presence of the delocalized nelectrons in the aromatic ring and the presence of polar compounds in the structure of these compounds. Approximately $20 \%$ of essential amino acids are structurally aromatic; interactions involving aromatic compounds are essential to biological recognition, including protein-ligand interaction [9]. Singh [57] reported that aromatic compounds are crucial in drug design as they engender improved efficacy and lead to optimization of the drug. The inhibitory potential of these derivates is consistent with results from other studies. The treatment of COVID-19-hospitalized adults with baricitinib, as well as dexamethasone, resulted in reduced mortality arising from the compounds' inhibitory potential [45].

The molecular docking studies revealed the binding pose of the compounds with the highest docking scores compared to the standard ligands. Analysis of the $3 \mathrm{D}$ and $2 \mathrm{D}$ structures of the docked SARS-CoV-2 target test compound complex showed that these compounds possess inhibitory potentials against the proteins. Compounds $\mathrm{C} 15, \mathrm{C} 12$, and C14, interacted with LEU A:271, LEU A:287, ASP A:289, GLU A:288, and LEU A:272 at the binding pocket of the SARS-CoV-2 Mpro, while its co-crystallized ligand, N3, interacted with GLN A:110, ASP A:153, ASP A:151, VAL A:104, and PHE A:294 (Figure 3). In this study, there was no interaction with CYS A: 145 and A: HIS 41, amino acids responsible for catalysis at the catalytic site of the main protease of SARS-CoV-2, as reported by Kneller et al. [58]. Present in the protease's catalytic dyads are other amino acids from CYS 145 and HIS 41, which are functional in eliminating Mpro enzymes. Dimerization and mutations of Mpro that engender enzymes with reduced activities are associated with interactions with the residues around GLU 288, ASP 289, and GLU 290 [59]. While CYS 145 and HIS 45 mediate the catalytic mechanism of the enzyme, mutation of these residues leads to the total annihilation of the Mpro activity $[60,61]$. Hence, the interactions of these compounds with GLU 288 and ASP 289 amongst other amino acids suggest that they could interfere with the catalytic activity of Mpro, inhibit SARS-CoV-2 replication, and ultimately eliminate Mpro by mutation or dimerization.

The SARS-CoV-2 Spro interacted with C13, C11, and C4 through critical amino acid residues, including the PHE A:486 of its receptor-binding domain (RBD) (Figure 4). PHE 486 has been identified as one of the critical residues that bind Spro to the ACE2 receptor [62]. PHE 486 of SARS-CoV-2 has similar biochemical properties to LEU 472 of SARS-CoV [60]. In addition, PHE 486 of the spike receptor-binding motif, through hydrophobic interactions, binds with the GLN24, LEU79, MET82, and TYR83 of ACE2 [60,63]. Moreover, from this study, the compounds- $\mathrm{C} 13, \mathrm{C} 11$, and C4-interacted similarly with the HIS A:540 and PRO A:415 residues of Spro RBD. Being similar in their structures to PHE, the heterocyclic and unsaturated structures of HIS and PRO could be responsible for the interaction. Therefore, pharmacological interaction between the test compounds and the critical amino acid residue, PHE A:486, could limit the binding of SARS-CoV-2 Spro to the ACE2 receptor host alveoli, thereby limiting viral entry and circumventing the progression of the disease.

Furthermore, C2, C8, and C11 demonstrated to be strong potential inhibitors of RdRp. Unlike the amino acid residue interaction with remdesivir, these compounds interacted with different and unique amino acids in the binding pocket of SARS-CoV2 RdRp (Figure 5). In this study, the test compounds interacted through conventional hydrogen bonds, halogen bonds, carbon-hydrogen bonds, alkyl interactions, and п-alkyl interactions with amino acids—VAL A:675, PRO A:677, SER A:709, ASP A:216, ASN A:209, TYR A:217, ILE A:37, PHE A:396, ARG A:457, CYS A:395, PRO A:461, ARG A:349, VAL 
A:315, HIS A:133, LYS A:47, SER A:709, HIS A:133, LYS A:780, TYR A:455, PRO A:620 and VAL A:315-present in the binding pocket of SARS-CoV-2. Kumar [64] similarly reported the amino acid residues-LYS47, ASN781, and SER709—in the binding pocket of SARS-CoV-2. Thus, Spro can potentially form hydrogen bonds with the drug molecule. In addition, RdRp plays an essential role in viral RNA translation, resulting in a protein that produces new virions from single-stranded RNA $[13,14]$. Hence, its inhibition by these heterocyclic compounds could offer therapeutic benefits against the SARS-CoV-2 growth and replication.

The accuracy of the docking protocol was validated by re-docking some of the standard and test ligands at a minimized energy back into the binding pocket of the drug targets. As previously stated, the re-docked pose almost completely overlapped the experimental orientation, indicating that AutoDock Vina on PyRx re-docked the standard and test ligands back into the binding pocket of the target proteins with a high degree of accuracy and precision. This demonstrates that the docking methodology used in this study is reliable and that the docking scores obtained are correct. Moreover, Ambrose et al. [50] validated this using a similar docking protocol by re-docking the co-crystallized ligand (PDB Ligand ID: 2WR) with the mutant EGFR (PDB: 3W2S) studied. It was evident in his study that there was a nearly perfect overlap of the re-docked ligands.

In addition to the inhibitory potentials demonstrated by the test compounds towards the drug targets, the compound possesses moderate ADMET properties. However, the compound may require lead optimization of its properties while maintaining its binding affinity. ADMET analysis is collectively known as absorption, distribution, metabolism, elimination, and toxicity. It is an analysis that determines whether a molecule can be easily absorbed, delivered to its target site of action, digested in a way that does not eliminate activity, and easily removed from the body while preventing toxic effects. A high-quality drug candidate should be effective against the therapeutic target and have appropriate ADMET properties at a therapeutic dose [65]. As a result, many in silico models for predicting chemical ADMET properties have been created and it has become advantageous as it reveals a pharmacokinetics-related failure of drugs before proceeding to the clinical phase [9].

Lipophilicity is generally considered a key determinant of permeability across tissue membranes, while water solubility is another physicochemical property that determines a drug's ADMET behaviours [9]. Orally administered drugs usually have a high lipophilic value, indicating easy passage and absorption through the intestinal lining, penetration of the membrane of the target cells, and travel in the blood. There is a direct relationship between the $\log \mathrm{P}$ value and lipophilicity, but this negatively correlates with water solubility [66]. Hence, the test compounds with Log P values between 3.27 and 4.10 (C4, C9, $\mathrm{C} 11, \mathrm{C} 12, \mathrm{C} 13, \mathrm{C} 14$, and C15) came out to be moderately soluble (Table 2). The presence of unsaturated structures, polar solar chains, and the higher molecular weights of the azeditine derivatives may have contributed to the moderate solubility of these compounds.

Drug-likeness is established based on chemical structures and physicochemical properties and is a qualitative assessment of oral bioavailability [67]. Moreover, Lipinski's Rule states that for an orally active drug, the following conditions must be obeyed: $\leq 5 \mathrm{H}$-bond donors, $\leq 10 \mathrm{H}$-bond acceptors, a molecular weight $\leq 500 \mathrm{~g} / \mathrm{mol}$, and a $\log p<5.43$; a ligand is considered orally inactive if it violates two or more of Lipinski's rules [68]. Considering these criteria, all the selected compounds (C4, C9, C11, C12, C13, C14, and C15) meet the requirements for oral bioavailability (Table 4). Moreover, none of the test compounds violated Veber's rule, whose criteria are the presence of rotatable bonds $\leq 10$ and polar surface (TPSA) area $\leq 140 \AA 2$ [69]. Moreover, evident from the bioavailability score of $0.55 \%$, all the selected test compounds will be good oral drugs (Table 4 ). This result shows the drug-likeness of these ligands compared to the standard and co-crystallized ligands.

According to the pharmacokinetic predictions of the compounds, all the test compounds were predicted to be inhibitors of CYP1A2, CYP2C19, CYP2C9, CYP2D6, and CYP3A4, except for compound C12, which is not an inhibitor of CYP2C9 (Table 3). Cy- 
tochrome P450 (CYP) is an isoenzyme superfamily that catalyzes various biochemical processes in phase I drug metabolism (Hollenberg, 2002). The inhibition of the five main isoforms-CYP1A2, CYP2C19, CYP2C9, CYP2D6, and CYP3A4-from eventually becoming the substrates of medications is a primary cause of pharmacokinetics-related drug-drug interactions $[66,70]$.

All the selected test compounds are predicted not to be substrates of Pgp, except compound C4. Pgp is an ATP-binding cassette transporter responsible for the active efflux of xenobiotics across biological membranes to protect the body against foreign toxins and to contribute to drug resistance [9]. This result infers that all the aforementioned compounds, aside from C4, are likely to be prevented from entering into their target sites of action due to the active efflux of the ATP-binding cassette. Nevertheless, the results of the toxicity prediction showed none of the compounds had tendencies towards any of the toxicity parameters tested. Therefore, the compounds could be considered for experimental studies and further development into novel drugs to treat SARS-CoV-2.

\section{Conclusions}

The heterocyclic ring derivatives were evaluated for their therapeutic potentials against SARS-CoV-2 Mpro, Spro, and RdRp. All the compounds reported showed excellent binding affinities with the various target proteins. Among the derivatives, compound C13 exhibits the highest binding affinity for the drug targets Spro $(-10.6 \mathrm{kcal} / \mathrm{mol})$ and $\mathrm{RdRp}$ $(-9.5 \mathrm{kcal} / \mathrm{mol})$, respectively. At a binding affinity of $-8.8 \mathrm{kcal} / \mathrm{mol}$, the compound C15 exhibits the highest binding affinity for Mpro. The compounds interacted with the LEU A:271, LEU A:287, ASP A:289, and LEU A:272 of Mpro and the HIS A:540, PRO A:415, PHE A:486, and LEU A:370 of the Spro receptor binding motif and some active site amino acids of RdRp. The compounds also possess a favourable ADMET profile and showed no tendency towards hERG inhibition, hepatotoxicity, carcinogenicity, mutagenicity, or drug-liver injury. These novel compounds could offer therapeutic benefits against SARS-CoV-2, and wet laboratory experiments are necessary to validate this computational study's results further.

Author Contributions: Conceptualization, B.A.B.; methodology, B.A.B.; software, B.A.B. and T.E.A.; validation, B.A.B., O.A.A., O.S.A. and T.E.A.; formal analysis, B.A.B.; investigation, B.A.B., T.E.A., O.A.A., O.S.A. and E.O.F.; resources, B.A.B., T.E.A. and O.A.A.; data curation, B.A.B., T.E.A. and E.O.F.; writing—original draft preparation, B.A.B.; writing—review and editing, B.A.B., T.E.A., O.A.A., O.S.A. and E.O.F.; visualization, B.A.B. and T.E.A.; supervision, B.A.B. and O.A.A.; project administration, B.A.B. and O.A.A.; funding acquisition, B.A.B. and O.A.A. All authors have read and agreed to the published version of the manuscript.

Funding: This research did not receive any specific grant from funding agencies in the public, commercial, or not-for-profit sectors.

Acknowledgments: The authors would like to acknowledge the healthcare frontline, scientists, and World Health Organization for their enormous contributions in combating coronavirus in Sub-Saharan Africa.

Conflicts of Interest: The authors declare that they have no known competing financial interests or personal relationships that could have influenced the work reported in this paper.

$\begin{array}{ll}\text { Abbreviations } & \\ \triangle G & \text { Change in free energy } \\ \text { ACE-2 } & \text { Angiotensin-converting Enzyme-2 } \\ \text { ADMET } & \text { Absorption, Distribution, Metabolism, Excretion, Toxicity } \\ \text { AMES } & \text { Ames Mutagenicity } \\ \text { ARG } & \text { Arginine } \\ \text { ASN } & \text { Asparagine } \\ \text { ATP } & \text { Adenosine Triphosphate }\end{array}$




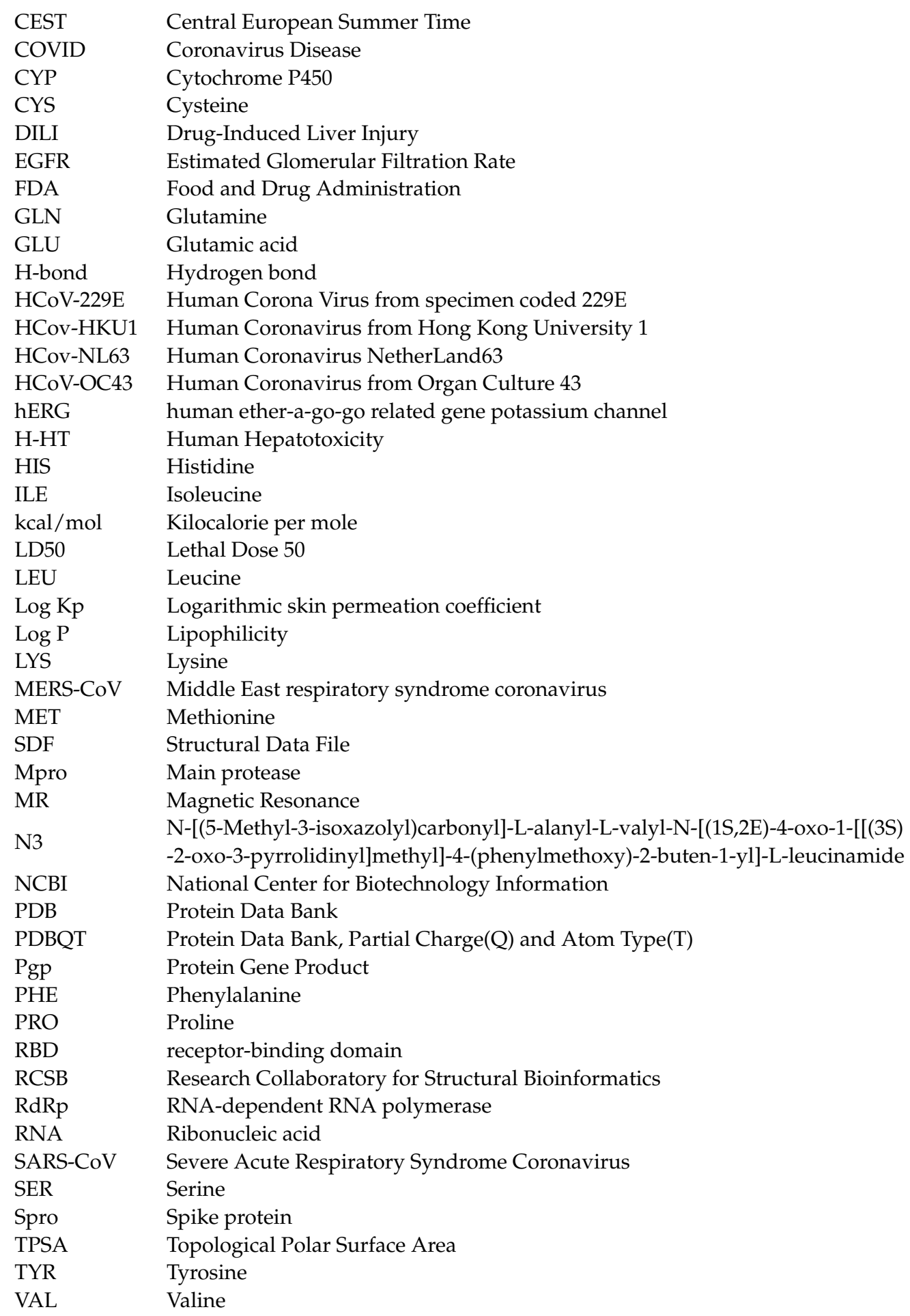

\section{References}

1. Amanat, F.; Krammer, F. SARS-CoV-2 vaccines: A status report. Immunity 2020, 52, 583-589. [CrossRef]

2. Wu, F.; Zhao, S.; Yu, B.; Chen, Y.M.; Wang, W.; Song, Z.G.; Hu, Y.; Tao, Z.W.; Tian, J.H.; Pei, Y.Y.; et al. A new coronavirus associated with human respiratory disease in China. Nature 2020, 579, 265-269. [CrossRef] [PubMed]

3. Zhu, N.; Zhang, D.; Wang, W.; Li, X.; Yang, B.; Song, J.; Zhao, X.; Huang, B.; Shi, W.; Lu, R.; et al. A novel coronavirus from patients with pneumonia in China, 2019. N. Engl. J. Med. 2020, 382, 727-733. [CrossRef]

4. Andersen, K.G.; Rambaut, A.; Lipkin, W.I.; Holmes, E.C.; Garry, R.F. The proximal origin of SARS-CoV-2. Nat. Med. 2020, 26, 450-452. [CrossRef]

5. Corman, V.M.; Muth, D.; Niemeyer, D.; Drosten, C. Hosts and sources of endemic human coronaviruses. Adv. Virus Res. 2018, 100, 163-188. 
6. World Health Organization-WHO. WHO Coronavirus (COVID-19) Dashboard. 2021. Available online: https://covid19.who.int/ (accessed on 11 October 2021).

7. Bager, P.; Ramussen, M.W.; Albertsen, M.; Krause, T.G. Hospitalisation associated with SARS-CoV-2 delta variant in Denmark. Lancet 2021, 21, 1351. [CrossRef]

8. Khan, A. Has the Delta Variant Changed the Symptoms of COVID-19? Aljazeera. 2021. Available online: https://www.aljazeera. $\mathrm{com} /$ features/2021/9/22/has-the-delta-variant-changed-the-symptoms-of-covid-19 (accessed on 23 September 2021).

9. Johnson, T.O.; Adegboyega, A.E.; Iwaloye, O.; Eseola, O.A.; Plass, W.; Afolabi, B.; Rotimi, D.; Ahmed, E.I.; Albrakati, A.; Batiha, G.E.; et al. Computational study of the therapeutic potentials of a new series of imidazole derivatives against SARS-CoV-2. J. Pharmacol. Sci. 2021, 147, 62-71. [CrossRef] [PubMed]

10. Boopathi, S.; Poma, A.B.; Kolandaivel, P. Novel 2019 coronavirus structure, mechanism of action, anti-viral drug promises and rule out against its treatment. J. Biomol. Struct. Dyn. 2021, 39, 3409-3418. [CrossRef]

11. Du, L.; He, Y.; Zhou, Y.; Liu, S.; Zheng, B.J.; Jiang, S. The spike protein of SARS-CoV-a target for vaccine and therapeutic development. Nat. Rev. Microbiol. 2009, 7, 226-236. [CrossRef]

12. Xia, S.; Yan, L.; Xu, W.; Agrawal, A.S.; Algaissi, A.; Tseng, C.K.; Wang, Q.; Du, L.; Tan, W.; Wilson, I.A.; et al. A pan-coronavirus fusion inhibitor targeting the HR1 domain of human coronavirus spike. Sci. Adv. 2019, 5, eaav4580. [CrossRef] [PubMed]

13. Ullrich, S.; Nitsche, C. The SARS-CoV-2 main protease as drug target. Bioorg. Med. Chem. Lett. 2020, 30, 127377. [CrossRef] [PubMed]

14. Wu, C.; Liu, Y.; Yang, Y.; Zhang, P.; Zhong, W.; Wang, Y.; Wang, Q.; Xu, Y.; Li, M.; Li, X.; et al. Analysis of therapeutic targets for SARS-CoV-2 and discovery of potential drugs by computational methods. Acta Pharm. Sin. B 2020, 10, 766-788. [CrossRef] [PubMed]

15. Ben-Shabat, S.; Yarmolinsky, L.; Porat, D.; Dahan, A. Anti-viral effect of phytochemicals from medicinal plants: Applications and drug delivery strategies. Drug Del. Trans. Res. 2020, 10, 354-367. [CrossRef]

16. Chang, K.O.; Kim, Y.; Lovell, S.; Rathnayake, A.D.; Groutas, W.C. Anti-viral drug discovery: Norovirus proteases and development of inhibitors. Viruses 2019, 11, 197. [CrossRef] [PubMed]

17. Elekofehinti, O.O.; Iwaloye, O.; Famusiwa, C.D.; Akinseye, O.; Rocha, J.B. Identification of main protease of coronavirus SARS-CoV-2 (Mpro) inhibitors from melissa officinalis. Curr. Drug Discov. Technol. 2020, 17, e17092020186048. [CrossRef] [PubMed]

18. Pillaiyar, T.; Meenakshisundaram, S.; Manickam, M. Recent discovery and development of inhibitors targeting coronaviruses. Drug Discov. Today 2020, 25, 668. [CrossRef]

19. Chukwudozie, O.S.; Duru, V.C.; Ndiribe, C.C.; Aborode, A.T.; Oyebanji, V.O.; Emikpe, B.O. The Relevance of Bioinformatics Applications in the Discovery of Vaccine Candidates and Potential Drugs for COVID-19 Treatment. Bioinform. Biol. Insights 2021, 15, 11779322211002168. [CrossRef]

20. Sumon, T.A.; Hussain, M.; Hasan, M.; Hasan, M.; Jang, W.J.; Bhuiya, E.H.; Chowdhury, A.A.M.; Sharifuzzaman, S.M.; Brown, C.L.; Kwon, H.J.; et al. A revisit to the research updates of drugs, vaccines, and bioinformatics approaches in combating COVID-19 pandemic. Front. Mol. Biosci. 2021, 7, 493. [CrossRef] [PubMed]

21. Tripathi, G.; Kumar, A.; Rajkhowa, S.; Tiwari, V.K. Synthesis of biologically relevant heterocyclic skeletons under solvent-free condition. In Green Synthetic Approaches for Biologically Relevant Heterocycles; Elsevier: Amsterdam, The Netherlands, 2021; pp. 421-459.

22. Babalola, B.A.; Adebami, G.E.; Akinsuyi, S.E. Mechanistic basis for Cancer Immune Evasion and role of immune checkpoint blockades in Immuno-Oncology. Glob. J. Cancer Ther. 2021, 7, 35-42. [CrossRef]

23. Kumura, K.; Wakiyama, Y.; Ueda, K.; Umemura, E.; Watanabe, T.; Kumura, M.; Yoshida, T.; Ajito, K. Synthesis and antibacterial activity of novel lincomycin derivatives. II. Exploring (7 S)-7-(5-aryl-1,3,4-thiadiazol-2-yl-thio)-7-deoxylincomycin derivatives. J. Antibiot. Res. 2017, 70, 655-663. [CrossRef] [PubMed]

24. Lv, K.; Sun, Y.; Sun, L.; Wei, Z.; Guo, H.; Wu, J.; Liu, M. Design, Synthesis, and in vitro Antibacterial Activity of Fluoroquinolone Derivatives Containing a Chiral 3-(Alkoxyimino)-2-(aminomethyl) azetidine Moiety. Chem. Med. Chem. 2012, 7, 1230-1236. [CrossRef] [PubMed]

25. Parmar, D.R.; Soni, J.Y.; Guduru, R.; Rayani, R.H.; Kusurkar, R.V.; Vala, A.G. Azetidines of pharmacological interest. Arch. Pharm. 2021, 354, e2100062. [CrossRef] [PubMed]

26. Tarr, J.C.; Wood, M.R.; Noetzel, M.J.; Melancon, B.J.; Lamsal, A.; Luscombe, V.B.; Rodriguez, A.L.; Byers, F.W.; Chang, S.; Cho, H.P.; et al. Challenges in the development of an M4 PAM preclinical candidate: The discovery, SAR, and biological characterization of a series of azetidine-derived tertiary amides. Bioorg. Med. Chem. Lett. 2017, 27, 5179-5184. [CrossRef] [PubMed]

27. Maetani, M.; Kato, N.; Jabor, V.A.; Calil, F.A.; Nonato, M.C.; Scherer, C.A.; Schreiber, S.L. Discovery of antimalarial Azetidine-2carbonitriles that inhibit P. falciparum dihydroorotate dehydrogenase. ACS Med. Chem. Lett. 2017, 8, 438-442. [CrossRef]

28. Maetani, M.; Zoller, J.; Melillo, B.; Verho, O.; Kato, N.; Pu, J.; Comer, E.; Schreiber, S.L. Synthesis of a bicyclic azetidine with in vivo antimalarial activity enabled by stereospecific, directed C (sp3)-H arylation. J. Am. Chem. Soc. 2017, 139, 11300-11306. [CrossRef] [PubMed] 
29. Johansson, A.; Lofberg, C.; Antonsson, M.; von Unge, S.; Hayes, M.A.; Judkins, R.; Ploj, K.; Benthem, L.; Linden, D.; Brodin, P.; et al. Discovery of (3-(4-(2-oxa-6-azaspiro [3.3] heptan-6-ylmethyl) phenoxy) azetidin-1-yl)(5-(4-methoxyphenyl)-1, 3, 4-oxadiazol2-yl) methanone (AZD1979), a melanin concentrating hormone receptor 1 (MCHr1) antagonist with favorable physicochemical properties. J. Med. Chem. 2016, 59, 2497-2511. [CrossRef] [PubMed]

30. Vemuri, V.K.; Janero, D.R.; Makriyannis, A. Pharmacotherapeutic targeting of the endocannabinoid signaling system: Drugs for obesity and the metabolic syndrome. Physiol. Behav. 2008, 93, 671-686.

31. Parmar, D.R.; Soni, J.Y.; Guduru, R.; Rayani, R.H.; Kusurkar, R.V.; Vala, A.G.; Talukdar, S.N.; Eissa, I.H.; Metwaly, A.M.; Khalil, A.; et al. Discovery of new anticancer thiourea-azetidine hybrids: Design, synthesis, in vitro antiproliferative, SAR, in silico molecular docking against VEGFR-2, ADMET, toxicity, and DFT studies. Bioorg. Chem. 2021, 115, 105206. [PubMed]

32. Metkar, S.D.; Bhatia, M.S.; Desai, U.V. Synthesis and biological evaluation of novel azetidine derivatives as dopamine antagonist. Med. Chem. Res. 2013, 22, 5982-5989. [CrossRef]

33. Hart, T.; Macias, A.T.; Benwell, K.; Brooks, T.; D’Alessandro, J.; Dokurno, P.; Francis, G.; Gibbons, B.; Haymes, T.; Kennett, G.; et al. Fatty acid amide hydrolase inhibitors. Surprising selectivity of chiral azetidine ureas. Bioorg. Med. Chem. Lett. 2009, 19, 4241-4244. [CrossRef] [PubMed]

34. Sharma, M.; Malhotra, N.; Yogavel, M.; Harlos, K.; Melilo, B.; Comer, E.; Gonse, A.; Parvez, S.; Mitasev, B.; Fang, F.G.; et al. Structural basis of malaria parasite phenylalanine tRNA-synthetase inhibition by bicyclic azetidines. Nat. Commun. 2021, 12, 343. [CrossRef]

35. Yue, P.; Lopez-Tapia, F.; Zhu, Y.; Brotherton-Pleiss, C.; Fu, W.; Alonso-Valenteen, F.; Mikhael, S.; Medina-Kauwe, L.; Tius, M.; Turkson, J. High-affinity azetidine-based small-molecules as a new class of direct inhibitors of STAT3 activity and breast cancer phenotype (abstract). In Proceedings of the American Association for Cancer Research Annual Meeting, Philadelphia, PA, USA, 10-15 April and 17-21 May 2021; Volume 81.

36. Kim, S.H.; Semenya, D.; Castagnolo, D. Antimicrobial drugs bearing guanidine moieties: A review. Eur. J. Med. Chem. 2021, 216, 113293. [CrossRef]

37. Shen, Y.; You, Q.; Wu, Y.; Wu, J. Inhibition of PAD4-mediated NET formation by cl-amidine prevents diabetes development in nonobese diabetic mice. Eur. J. Pharmacol. 2021, 174623. [CrossRef] [PubMed]

38. Čikoš, A.; Dragojević, S.; Kubiček, A. Degradation products of azetidine core G334089-Isolation, structure elucidation and pathway. J. Pharm. Biomed. Anal. 2021, 203, 114232. [CrossRef] [PubMed]

39. Bialer, M.; Yagen, B.; Mechoulam, R.; Becker, Y. Structure-activity relationships of pyrrole amidine antiviral antibiotics. 2. Preparation of mono-and tripyrrole derivatives of congocidine. J. Med. Chem. 1980, 23, 1144-1148. [CrossRef]

40. Naesens, L.; Guddat, L.W.; Keough, D.T.; van Kuilenburg, A.B.; Meijer, J.; Voorde, J.V.; Balzarini, J. Role of human hypoxanthine guanine phosphoribosyltransferase in activation of the antiviral agent T-705 (favipiravir). Mol. Pharmacol. 2013, 84, 615-629. [CrossRef] [PubMed]

41. Dos Santos, G.C.; Martins, L.M.; Bregadiolli, B.A.; Moreno, V.F.; da Silva-Filho, L.C.; da Silva, B.H.S.T. Heterocyclic compounds as anti-viral drugs: Synthesis, structure-activity relationship and traditional applications. J. Heterocycl. Chem. 2021. [CrossRef]

42. Głowacka, I.E.; Grabkowska-Drużyc, M.; Andrei, G.; Schols, D.; Snoeck, R.; Witek, K.; Podlewska, S.; Handzlik, J.; Piotrowska, D.G. Novel N-Substituted 3-Aryl-4-(diethoxyphosphoryl)azetidin-2-ones as Antibiotic Enhancers and Antiviral Agents in Search for a Successful Treatment of Complex Infections. Int. J. Mol. Sci. 2021, 22, 8032. [CrossRef]

43. Hasan, M.J.; Rabbani, R.; Anam, A.M.; Huq, S.M.R.; Polash, M.M.I.; Nessa, S.S.T.; Bachar, S.C. Impact of high dose of baricitinib in severe COVID-19 pneumonia: A prospective cohort study in Bangladesh. BMC Infect Dis. 2021, 21, 427. [CrossRef] [PubMed]

44. Boghuma, K.T.; Monica, M.F.; Ashish, M.; Randi, C.S.; Abeer, M.; Sushma, K.C.; Jesse, O.S.; Kathryn, D.S.; Bonnie, C.; Alex, E.; et al. Use of Baricitinib in Patients with Moderate to Severe Coronavirus Disease 2019. Arch. Clin. Infect. Dis. 2021, 72, 1247-1250. [CrossRef]

45. Marconi, V.C.; Ramanan, A.V.; de Bono, S.; Kartman, C.E.; Krishnan, V.; Liao, R.; Piruzeli, M.L.B.; Goldman, J.D.; AlatorreAlexander, J.; de Cassia Pellegrini, R.; et al. Efficacy and safety of baricitinib for the treatment of hospitalised adults with COVID-19 (COV-BARRIER): A randomised, double-blind, parallel-group, placebo-controlled phase 3 trial. Lancet Respir. Med. 2021, 9, 1407-1418. [CrossRef]

46. Kalil, A.C.; Patterson, T.F.; Mehta, A.K.; Tomashek, K.M.; Wolfe, C.R.; Ghazaryan, V.; Marconi, V.C.; Ruiz-Palacios, G.M.; Hsieh, L.; Kline, S.; et al. Baricitinib plus remdesivir for hospitalized adults with Covid-19. N. Engl. J. Med. 2021, 384, 795-807. [CrossRef]

47. O'Boyle, N.M.; Banck, M.; James, C.A.; Morley, C.; Vandermeersch, T.; Hutchison, G.R. Open Babel: An open chemical toolbox. J. Cheminfor 2011, 3, 33. [CrossRef] [PubMed]

48. Dong, J.; Cao, D.S.; Miao, H.Y.; Liu, S.; Deng, B.C.; Yun, Y.H.; Wang, N.N.; Lu, A.P.; Zeng, W.B.; Chen, A.F. ChemDes: An integrated web-based platform for molecular descriptor and fingerprint computation. J. Cheminform. 2015, 7, 60. [CrossRef] [PubMed]

49. Trott, O.; Olson, A.J. AutoDock Vina: Improving the speed and accuracy of docking with a new scoring function, efficient optimization, and multithreading. J. Comput. Chem. 2010, 31, 455-461. [CrossRef]

50. Ambrose, G.O.; Afees, O.J.; Nwamaka, N.C.; Simon, N.; Oluwaseun, A.A.; Soyinka, T.; Oluwaseun, A.S.; Bankole, S. Selection of Luteolin as a potential antagonist from molecular docking analysis of EGFR mutant. Bioinformation 2018, 14, 241-247. [CrossRef]

51. Dong, J.; Wang, N.N.; Yao, Z.J.; Zhang, L.; Cheng, Y.; Ouyang, D.; Lu, A.P.; Cao, D.S. ADMETlab: A platform for systematic ADMET evaluation based on a comprehensively collected ADMET database. J. Cheminform. 2018, 10, 29. [CrossRef] 
52. Singh, S.; Khera, D.; Chugh, A.; Khera, P.S.; Chugh, V.K. Efficacy and safety of remdesivir in COVID-19 caused by SARS-CoV-2: A systematic review and meta-analysis. BMJ Open 2021, 11, e048416. [CrossRef]

53. Young, B.; Tan, T.T.; Leo, Y.S. The place for remdesivir in COVID-19 treatment. Lancet Infect. Dis. 2021, 21, 20-21. [CrossRef]

54. Liu, L.; Hu, Y.; Shen, Y.F.; Wang, G.X.; Zhu, B. Evaluation on anti-viral activity of coumarin derivatives against spring viraemia of carp virus in epithelioma papulosum cyprini cells. Antivir. Res. 2017, 144, 173-185. [CrossRef] [PubMed]

55. Mandal, M.K.; Ghosh, S.; Naesens, L.; Bhat, H.R.; Singh, U.P. Facile synthesis, antimicrobial and anti-viral evaluation of novel substituted phenyl 1, 3-thiazolidin-4-one sulfonyl derivatives. Bioorg. Chem. 2021, 114, 105153. [CrossRef] [PubMed]

56. Kanwal, A.; Ahmad, M.; Aslam, S.; Naqvi, S.A.R.; Saif, M.J. Recent advances in anti-viral benzimidazole derivatives: A mini review. Pharmaceut. Chem. J. 2019, 53, 179-187. [CrossRef]

57. Singh, V.P. Aromatic interactions in biological systems. Sci. Technol. Jpn. 2015, 3, 42-48.

58. Kneller, D.W.; Phillips, G.; Weiss, K.L.; Pant, S.; Zhang, Q.; O’Neill, H.M.; Coates, L.; Kovalevsky, A. Unusual zwitterionic catalytic site of SARS-CoV-2 main protease revealed by neutron crystallography. J. Biol. Chem. 2020, 295, 17365-17373. [CrossRef]

59. Novak, J.; Rimac, H.; Kandagalla, S.; Pathak, P.; Grishina, M.; Potemkin, V. Proposition of a new allosteric binding site for potential SARS-CoV-2 3CL protease inhibitors by utilizing molecular dynamics simulations and ensemble docking. J. Biomol. Struct. Dyn. 2020, 1-14. [CrossRef]

60. Lan, J.; Ge, J.; Yu, J.; Shan, S.; Zhou, H.; Fan, S.; Zhang, Q.; Shi, X.; Wang, Q.; Zhang, L.; et al. Structure of the SARS-CoV-2 spike receptor-binding domain bound to the ACE2 receptor. Nature 2020, 581, 215-220. [CrossRef] [PubMed]

61. Yan, R.; Zhang, Y.; Li, Y.; Xia, L.; Guo, Y.; Zhou, Q. Structural basis for the recognition of SARS-CoV-2 by full-length human ACE2. Science 2020, 367, 1444-1448. [CrossRef]

62. Pagadala, N.S.; Landi, A.; Maturu, P.; Tuszynski, J. In silico identification of RBD subdomain of spike protein from Pro322-Thr581 for applications in vaccine development against SARS-CoV2. J. Mol. Struct. 2021, 1240, 130534. [CrossRef]

63. López-Cortés, G.I.; Palacios-Pérez, M.; Zamudio, G.S.; Velediaz, H.F.; Ortega, E.; Jose, M.V. Neutral evolution test of the spike protein of SARS-CoV-2 and its implications in the binding to ACE2. Sci. Rep. 2021, 11, 18847. [CrossRef] [PubMed]

64. Kumar, G.P. Conformational Analysis between 6M71 (SARS COV2 RNA-Dependent RNA Polymerase) and CHEMBL3120791 using GROMACS Molecular Dynamic Simulation. 2021. Available online: https://chemrxiv.org/engage/api-gateway/ chemrxiv/assets/orp/resource/item/60e1686a9bb5dd588390ddef/original/conformational-analysis-between-6m71-sarscov2-rna-dependent-rna-polymerase-and-chembl3120791-using-gromacs-molecular-dynamic-simulation.pdf (accessed on 17 August 2021).

65. Guan, L.; Yang, H.; Cai, Y.; Sun, L.; Di, P.; Li, W.; Liu, G.; Tang, Y. ADMET-score-A comprehensive scoring function for evaluation of chemical drug-likeness. MedChem Comm 2018, 10, 148-157. [CrossRef] [PubMed]

66. Daina, A.; Michielin, O.; Zoete, V. SwissADME: A free web tool to evaluate pharmacokinetics, drug-likeness and medicinal chemistry friendliness of small molecules. Sci. Rep. 2017, 7, 42717. [CrossRef]

67. Ursu, O.; Rayan, A.; Goldblum, A.; Oprea, T.I. Understanding drug-likeness. WIREs Comput. Mol. Sci. 2011, 1, 760-781. [CrossRef]

68. Lipinski, C.A.; Lombardo, F.; Dominy, B.W.; Feeney, P.J. Experimental and computa-tional approaches to estimate solubility and permeability in drug discovery and development settings. Adv. Drug Deliv. Rev. 1997, 23, 3-26. [CrossRef]

69. Veber, D.F.; Johnson, S.R.; Cheng, H.Y.; Smith, B.R.; Ward, K.W.; Kopple, K.D. Molecularproperties that influence the oral bioavailability of drug candidates. J. Med. Chem. 2002, 45, 2615-2623. [CrossRef] [PubMed]

70. Huang, S.M.; Strong, J.M.; Zhang, L.; Reynolds, K.S.; Nallani, S.; Temple, R.; Abraham, S.; al Habet, S.; Baweja, R.K.; Burckart, G.J.; et al. New era in drug interaction evaluation: US Food and Drug Administration update on CYP enzymes, transporters, and the guidance process. J. Clin. Pharmacol. 2008, 48, 662-670. [CrossRef] 